\title{
Emergency contraception: current options, challenges, and future directions
}

\author{
This article was published in the following Dove Press journal: \\ Open Access Journal of Contraception \\ 7 October 20II \\ Number of times this article has been viewed
}

\author{
Serena Dovey \\ Joseph Sanfilippo \\ Magee Women's Hospital, \\ University of Pittsburgh Medical \\ Center, Pittsburgh, PA, USA
}

Correspondence: Serena Dovey Magee Women's Hospital, 300 Halket Street, Suite 2309, Pittsburgh, PA I52 I3, USA

Tel + I 4I2 64| I204

Fax + | 4I264| II33

Email doveysl@upmc.edu

\begin{abstract}
The term emergency contraception (EC) refers to utilizing a medication or placing a copper intrauterine device within a short time interval after unprotected intercourse in order to prevent pregnancy. Established methods of EC include the Yuzpe regimen, levonorgestrel, and placement of a copper intrauterine device. Recently, ulipristal acetate, a selective progesterone receptor modulator, has been examined in several large-scale clinical trials and been shown to have comparable if not improved efficacy over the levonorgestrel regimen, which is the most commonly used form of EC today. EC has increased in efficacy since its advent with the Yuzpe regimen several decades ago, and many have expressed hope that widespread utilization of EC will lead to a decreased abortion rate worldwide. However, despite increased access to EC over the past several years, many barriers still exist in regards to allowing EC to be widely available to women wishing to prevent unplanned pregnancies. Future research must focus on addressing such barriers in order to realize the potential of EC to decrease abortion rates worldwide. This review article will address the current options for EC, describe current challenges in the field, and highlight future avenues of research.
\end{abstract}

Keywords: emergency contraception, levonorgestrel, ulipristal acetate, Yuzpe regimen

\section{Introduction}

In the US, it is estimated that approximately $50 \%$ of pregnancies are unintended, and about half of such unintended pregnancies end in abortion. ${ }^{1}$ Teen pregnancies contribute significantly to this number, with approximately 750,000 teens aged 15-19 years becoming pregnant in the US each year. Minority populations, most notably African Americans and Hispanics, contribute disproportionately to such unintended pregnancies. ${ }^{2}$ The unplanned pregnancy rate worldwide is not much better; of the 210 million established pregnancies each year, about $40 \%$ are unintended. ${ }^{3}$ Such statistics point to the importance of making emergency contraception (EC) widely available and easily accessible to women to provide a means to help reduce the unintended pregnancy rate. However, access to EC is not the only obstacle encountered in the campaign to decrease unintended pregnancies. This paper reviews the current EC options available today, challenges in making effective and efficient use of EC, and future directions of research.

\section{Indications for EC}

EC refers to utilizing a medication or placing a copper intrauterine device (IUD) within a short time interval after unprotected intercourse in order to prevent pregnancy. EC is also referred to as the "morning-after pill" or "post-coital contraception," but experts 
in the field discourage the use of such terminology for fear that it may breed confusion regarding the timing of when EC can be used. ${ }^{4} \mathrm{EC}$ is indicated in situations where other contraceptive methods have failed or when no contraceptive method was used in women who do not desire pregnancy. Examples of contraceptive failure include when a condom breaks or slips, missing two or more doses of a combined oral contraceptive pill, taking a progestin-only pill more than three hours late, being more than two weeks late in repeat administration of depot medroxyprogesterone acetate, or when dislodgement or breakage of a barrier method (diaphragm or cervical cap) occurs. ${ }^{5}$

One important fact for all women's health providers to remember is that there are no absolute contraindications to EC for any woman of reproductive age desiring to prevent pregnancy. The World Health Organization (WHO) describes no medical circumstance in which the risks of EC outweigh the advantages of preventing pregnancy. ${ }^{6,7}$ Even in medical conditions for which combined oral contraceptives have been deemed contraindicated, such as cardiovascular disease, migraine, or liver disease, it is not necessary to withhold EC. Drug options for EC generally include levonorgestrel alone, the combined estrogen-progestin (Yuzpe) regimen, and selective progesterone receptor modulators-antiprogestins. However, accessibility of each of these regimens varies by country. The levonorgestrel regimen is currently the most widely available form of EC and is marketed specifically for this purpose. Placement of a copper IUD represents a mechanical option to avoid unwanted pregnancy following unprotected intercourse, and can also function as a long-term contraceptive method.

\section{Yuzpe regimen}

The idea of being able to prevent pregnancy after unprotected intercourse is not a novel concept and has been around for several decades. In the 1970 s, the first effective means of postcoital contraception was introduced and involved administration of higher doses of combined oral contraceptive pills containing ethinyl estradiol and either levonorgestrel or norgestrel. This initial development in the field of EC is accredited to Dr Albert Yuzpe, a Canadian physician who described the use of a combination of ethinyl estradiol $0.2 \mathrm{mg}$ with norgestrel $2 \mathrm{mg}$ taken in two divided doses 12 hours apart, with the first dose administered within 72 hours following unprotected intercourse. ${ }^{8}$ In one series of 608 patients, only one patient became pregnant from presumed method failure. ${ }^{8}$ This regimen became coined the "Yuzpe regimen," and was very popular back in the 70s and 80s.
However, as described in more detail below, subsequent studies have demonstrated the levonorgestrel regimen to be more effective with fewer side effects, ${ }^{9}$ so the Yuzpe regimen is no longer the first-line recommendation for EC. Given the relatively high doses of ethinyl estradiol in the Yuzpe regimen, common side effects include nausea and vomiting, with reported incidences close to $50 \%$ and $20 \%$, respectively. ${ }^{9}$ Indeed, it is often recommended that women take an antiemetic in conjunction with the Yuzpe regimen, given the high incidence of gastrointestinal side effects. However, one benefit to the Yuzpe regimen is that the appropriate doses of ethinyl estradiol and levonorgestrel or norgestrel can be obtained through a variety of combined oral contraceptive pills on the market today. Thus, for women who feel uncomfortable seeking medication for EC purposes or have privacy concerns, the Yuzpe regimen could potentially be used with combined oral contraceptive pills they already take for long-term contraception. Additionally, in some countries with restricted licensing of other EC methods, the Yuzpe regimen may be the only available EC option available to women wishing to prevent an undesired pregnancy. ${ }^{10}$

\section{Levonorgestrel Efficacy}

In the original studies, the levonorgestrel regimen, marketed as plan $\mathrm{B}^{\circledR}$ in the US, was studied as two doses of levonorgestrel $0.75 \mathrm{mg}$ taken 12 hours apart. In a landmark study, this levonorgestrel regimen was compared with the more traditional Yuzpe regimen and was demonstrated to have comparable efficacy when taken within 72 hours of unprotected intercourse (failure rate $2.4 \%$ in the levonorgestrel group versus $2.6 \%$ in the Yuzpe group) as well as an improved side effect profile. ${ }^{11}$ Indeed, the incidence of nausea, vomiting, and fatigue was significantly lower in the group treated with levonorgestrel alone. A second, larger, randomized, doubleblind controlled trial enrolling just under 2000 women at 21 centers repeated the comparison of the levonorgestrel regimen taken within 72 hours following unprotected intercourse with the Yuzpe regimen and demonstrated the superiority of the levonorgestrel regimen (pregnancy rate $1.1 \%$ in the levonorgestrel group versus 3.2\% in the Yuzpe group). ${ }^{9}$ By estimating the expected number of pregnancies if EC had not been used, the authors concluded that the levonorgestrel regimen was $85 \%$ effective in preventing pregnancy.

More recent studies have demonstrated that a single $1.5 \mathrm{mg}$ dose of levonorgestrel was as effective as the $0.75 \mathrm{mg}$ divided dose regimen without changing the side 
effect profile. ${ }^{12,13}$ Additionally, in the large trial conducted by the WHO in 2002 using a three-arm comparison of the two levonorgestrel dosing regimens as well as a single $10 \mathrm{mg}$ dose of mifepristone, the investigators demonstrated that all regimens retained some efficacy up to 120 hours following unprotected intercourse. ${ }^{13}$ Currently, plan B One Step ${ }^{\circledR}$ (the single $1.5 \mathrm{mg}$ dose of levonorgestrel) is licensed in the US to be used within 72 hours of unprotected intercourse.

Interestingly, the reported efficacy of the levonorgestrel regimen has recently been suggested to have been somewhat inflated in earlier studies due to the way in which the expected number of pregnancies was determined. Given that no trial for EC has ever randomized women to a placebo group where no medication was given, and it would be unethical to do so, studies to date have had to estimate the number of pregnancies prevented to determine the actual efficacy of EC methods. Some investigators have argued that the expected number of pregnancies used in some studies are based on conception rates in women who are attempting pregnancy, and for a variety of reasons, such conception rates are likely to be higher than in a population seeking EC. ${ }^{14}$ For example, some women seek EC following contraceptive failure, and the risk of pregnancy in this situation is likely to be less than if no contraception was used. Additionally, some trials have estimated the day of ovulation by counting backwards from the subsequent menses. Given that hormonal methods of EC can influence when menses begins, this is an inaccurate way to determine ovulation dating in these trials.

By using different estimates of pregnancy risk based on cycle day (where cycle day 1 is when menses begins in the cycle where EC is used), Trussell et al demonstrated that the efficacy rate for the Yuzpe regimen reported in two of the largest trials (conducted by the WHO and the Population Counsel $)^{9,15}$ was likely overestimated by approximately $10 \% .{ }^{16} \mathrm{~A}$ follow-up study, using this new set of conception probabilities, argued that the levonorgestrel regimen prevents at least $49 \%$ of expected pregnancies if one makes the assumption that the Yuzpe regimen (its comparator) was completely ineffective at preventing pregnancy. ${ }^{14}$ However, given that there is good evidence that the Yuzpe regimen has some efficacy in preventing pregnancy following unprotected intercourse, it is likely that the levonorgestrel regimen actually prevents significantly more than $49 \%$ of expected pregnancies.

\section{Mechanism of action}

The mechanism through which the levonorgestrel regimen prevents pregnancy is thought to work primarily through disruption or delay in ovulation. Studies assessing follicular development and ovulation in association with timing of levonorgestrel administration have demonstrated that levonorgestrel is very effective at delaying or blocking ovulation when taken before the luteinizing hormone surge. However, once the luteinizing hormone surge has been initiated, levonorgestrel is not effective at disrupting ovulation. ${ }^{17-19}$ Although it has been debated whether the levonorgestrel regimen has other mechanisms through which it is able to prevent pregnancy, such as effects on sperm function, tubal transport, and endometrial receptivity, data to support such propositions have not been found. ${ }^{19}$ In vitro studies have demonstrated that sperm function is not affected by the doses of levonorgestrel used in EC, and viable sperm have been found in the genital tract of women 24-48 hours after taking levonorgestrel. ${ }^{20-22}$ Furthermore, several studies have now established that endometrial receptivity does not appear to be affected by the levonorgestrel regimen. ${ }^{19,23,24}$

In an interesting study performed by Novikova et al women who presented for EC were treated with the single $1.5 \mathrm{mg}$ dose of levonorgestrel, and immediately before taking the medication, blood was drawn to assess timing of ovulation (via measurement of luteinizing hormone, estradiol, and progesterone). ${ }^{25}$ The authors demonstrated that, among women who had unprotected intercourse either the day prior to or on the day of ovulation, 3-4 pregnancies would be anticipated, and three pregnancies resulted. The women in this group took levonorgestrel approximately 2 days after ovulation. However, in women who had unprotected intercourse 2-5 days prior to ovulation, and thus took levonorgestrel prior to ovulation, four pregnancies would be expected based on the number of women in the study, but no pregnancies were observed. This study lends clinical support to the idea that ovulation is effectively delayed or inhibited when levonorgestrel is taken after recruitment of a dominant follicle but prior to initiation of the luteinizing hormone surge. However, the levonorgestrel regimen appears to have little to no effect in pregnancy prevention when taken after the onset of the luteinizing hormone surge. Thus, the levonorgestrel regimen has a fairly narrow therapeutic window during which it is efficacious. ${ }^{19} \mathrm{~A}$ similar study by Noe et al confirmed that levonorgestrel taken on or after the day of ovulation is ineffective in preventing pregnancy. ${ }^{26}$

\section{Side effects}

In general, the side effect profile of the levonorgestrel regimen is favorable, especially when compared with the earlier 
Yuzpe regimen. The most common side effects reported in the large trials included gastrointestinal symptoms, such as nausea, abdominal pain, vomiting, and diarrhea, with the incidence of nausea and vomiting being approximately $18 \%$ and 4\%, respectively. ${ }^{7,9,12,13}$ Given the fairly low incidence of vomiting, routine use of antiemetics with the levonorgestrel regimen is not necessary. Additionally, side effects such as headache, fatigue, and dizziness, are occasionally reported. ${ }^{5,9,13}$ Menstrual irregularities and irregular bleeding have also been described in association with the use of the levonorgestrel regimen.

Generally, women will have their menstrual period within 1 week either before or after the expected time. ${ }^{9}$ However, menstrual bleeding with levonorgestrel is delayed less frequently than it is when using progesterone receptor modulators, which is cited as a benefit of the levonorgestrel regimen, because delay in menses can often provoke anxiety about possible pregnancy. Indeed, in a randomized trial comparing ulipristal acetate, a progesterone receptor modulator, with the levonorgestrel regimen, menses was delayed by 2.1 days in the group who took ulipristal whereas the group who took levonorgestrel had menstrual bleeding 1.2 days earlier than expected. ${ }^{27}$ Levonorgestrel can also cause nonmenstrual bleeding in the week after use. ${ }^{7,13}$ Irregular bleeding associated with EC is transient.

\section{Precautions}

Contraceptive medications are some of the most thoroughly studied drugs on the market today, and the safety of the levonorgestrel regimen has been well established. As mentioned earlier, there are no definitive contraindications to utilizing the levonorgestrel regimen for prevention of an unwanted pregnancy, and the WHO Medical Eligibility Criteria for Contraceptive Use lists no contraindications to the levonorgestrel system for EC. ${ }^{4,6}$ Indeed, the levonorgestrel regimen can currently be obtained in many countries without a prescription. However, it has been suggested that levonorgestrel may not be well absorbed in women with Crohn's disease. ${ }^{4}$ Additionally, a theoretical risk exists that the standard dose may have decreased efficacy in women using medications that induce liver enzymes, such as antiepileptics, antiretrovirals, antifungals, and certain antibiotics. Some experts have suggested that women taking such medication should double the dose of levonorgestrel to $3 \mathrm{mg}$ taken within 72 hours following unprotected intercourse, but there are no published data currently to back this recommendation. ${ }^{4}$ Finally, using the levonorgestrel system when a woman is known to be pregnant or suspects that she might be is a contraindication to its use. However, taking levonorgestrel with an established pregnancy will not disrupt the pregnancy, and it is not associated with an increased risk of birth defects if taken during pregnancy. ${ }^{5,7,28}$

\section{Counseling points}

As discussed further below, one of the challenges to making EC more widely utilized is the lack of knowledge on the part of both women and, to some degree, women's health providers, regarding its use. When discussing the levonorgestrel regimen for EC with patients, it is important for providers to emphasize the following points:

- The levonorgestrel regimen is most effective when taken as soon as possible following unprotected intercourse. Some evidence suggests that efficacy decreases with increasing time between unprotected intercourse and taking the medication. ${ }^{11,13}$

- Because delay in ovulation is the primary mechanism through which levonorgestrel acts, patients must be warned that they are at continued risk of pregnancy if they engage in additional acts of unprotected intercourse after taking levonorgestrel.

- The levonorgestrel regimen is not as effective at preventing pregnancy as other methods developed for long-term contraception, and it should not be used as the only means of contraception. ${ }^{4,7}$ Patients should be counseled to begin using an appropriate long-term contraceptive method, or, if contraceptive failure occurred, patients should be advised about how to avoid such contraceptive failures in the future.

- Given that the levonorgestrel regimen does not protect against pregnancy with future acts of unprotected intercourse, even in the same menstrual cycle, patients should be counseled to begin a barrier contraceptive method immediately after taking levonorgestrel. Additionally, hormonal contraceptive methods such as combined oral contraceptive pills can be started immediately after taking levonorgestrel, so long as a barrier method of contraception is also used until the next menstrual period. Longer-term hormonal options, such as the levonorgestrel IUD, depot medroxyprogesterone acetate (Depo-Provera ${ }^{\circledR}$ ), or the progestin implant $\left(\right.$ Implanon $^{\circledR}$ ) should only be started after the patient's next menstrual period to ensure that she is not pregnant. ${ }^{7}$

- There is no need for a scheduled follow-up visit after using the levonorgestrel regimen, but patients should be 
advised that if their next menstrual period is delayed by a week or more that they should test for pregnancy. 4,7

- The levonorgestrel regimen does not protect against sexually transmitted infections (STIs). ${ }^{4,5,7}$ In fact, no current method of EC protects against STIs.

Additionally, it is important for providers to keep in mind the following points when discussing or prescribing the levonorgestrel regimen for $\mathrm{EC}$ :

- No examination or screening tests are necessary to prescribe the levonorgestrel regimen. ${ }^{7}$

- It is not necessary to obtain a pregnancy test routinely prior to prescribing levonorgestrel for EC. ${ }^{7}$ A pregnancy test should be sought only if there is reason to believe the patient may already be pregnant.

- Taking levonorgestrel will not interrupt an already established pregnancy, and it is not associated with an increased risk of teratogenicity if taken during pregnancy. ${ }^{4,5,7}$

- The levonorgestrel regimen does not increase the risk of an ectopic pregnancy. ${ }^{5,7,29}$

- All women who are victims of sexual assault should be offered EC. Sadly, some studies have suggested that less than half of women who present to the emergency room in the US following sexual assault receive EC. $7,30,31$

\section{Copper intrauterine device}

Insertion of a copper IUD is another effective method of $\mathrm{EC}$, and the indications for its use are the same as for other methods of EC. One touted benefit of utilizing the copper IUD as EC is that it has been shown to be quite effective in preventing pregnancy for up to 5 days after unprotected intercourse, or for up to 5 days following ovulation, whereas some studies have suggested decreasing efficacy over time with the levonorgestrel regimen. ${ }^{4,711,13}$ In addition, women can maintain the copper IUD as a long-term contraceptive method after placement, and studies have demonstrated that the vast majority of women who have a copper IUD placed for EC keep them in place for continued contraception. ${ }^{32}$ Additionally, some advocate the copper IUD as the mechanism of choice in women taking medications that can induce liver enzymes. ${ }^{4}$ However, one drawback to utilizing the copper IUD for EC is that it involves placement in a clinical setting by a health care professional, thus necessitating that women present for evaluation and placement within a short time period following unprotected intercourse, limiting the availability of this option.

The copper IUD has been shown to be very effective in preventing pregnancy when placed within 5 days following unprotected intercourse, and prospective cohort trials have reported a pregnancy rate around $0 \%-0.2 \%{ }^{4,7,32,33}$ One mechanism through which the copper IUD acts to prevent pregnancy is via prevention of fertilization. Studies have demonstrated that the copper released is toxic to both sperm and ovulated oocytes, and it also acts at the level of the cervical mucus to decrease sperm penetration. ${ }^{4,34}$ Additionally, the copper IUD creates an inflammatory reaction within the endometrium, impairing implantation. ${ }^{4,35,36}$ Contraindications to utilizing the copper IUD as EC are the same as when used as routine contraception, and include a current STI or pelvic inflammatory disease. ${ }^{4}$ Nulliparity and young age are not contraindications. One question that often arises regarding placement of a copper IUD for EC is whether screening for STIs is necessary in this situation. Importantly, placement of the IUD should never be delayed in order to obtain culture results. In nonemergent situations, the WHO recommends performing an STI risk assessment prior to IUD placement. The Faculty of Sexual and Reproductive Healthcare of the Royal College of Obstetricians and Gynecologists recommends screening women for Chlamydia trachomatis prior to IUD insertion in women at risk and in all women who request screening. ${ }^{4}$ Some studies have suggested that positive Chlamydia cultures obtained at the time of IUD insertion are at low risk of developing pelvic inflammatory disease if the Chlamydia is treated with the IUD in place. ${ }^{37}$ Finally, it is important to remember that it is only the copper IUD that can be utilized for EC, because the levonorgestrel IUD is not effective for this indication..$^{4,7}$

\section{Selective progesterone receptor modulation}

One of the most recent medications to enter the EC arena is the progesterone receptor modulator, ulipristal acetate, which was approved by the US Food and Drug Administration (FDA) in August 2010 for use as an emergency contraceptive, and marketed under the trade name ella ${ }^{\circledR}$. The same medication has been available in Europe, marketed under the name ellaOne $^{\circledR}$, since May 2009. Ulipristal acetate is a secondgeneration progesterone receptor modulator. ${ }^{38}$ Mifepristone, a first-generation progesterone receptor modulator, is known to be quite efficacious at preventing pregnancy when taken as a single dose within 120 hours following unprotected intercourse. ${ }^{4,13,39}$ However, mifepristone is also used to induce medical abortions, and thus, for various social and political reasons, has not been approved for use as an emergency contraceptive agent in many countries.

In a large, randomized, controlled trial conducted by Crenin et al ulipristal acetate was found to be at least 
as efficacious at preventing pregnancy as the split-dose levonorgestrel regimen when take within 72 hours following unprotected intercourse. ${ }^{38}$ Pregnancy rates of $0.9 \%$ and $1.7 \%$ were reported in the ulipristal acetate and levonorgestrel groups, respectively, demonstrating that $85 \%$ and $69 \%$ of pregnancies in each group were estimated to have been prevented by the respective medications. A study performed by Fine et al examined the efficacy of ulipristal acetate in preventing pregnancy when taken 48-120 hours after unprotected intercourse, and reported a pregnancy rate of only $2.1 \%$ among 1241 enrolled women. ${ }^{40}$ Moreover, the efficacy of ulipristal acetate did not diminish with increasing time of administration from unprotected intercourse, with reported pregnancy rates of $2.3 \%, 2.1 \%$, and $1.3 \%$ in the 48-72-hour, 72-96-hour, and over 96-hour time intervals, respectively.

Finally, in a recent report, the efficacy of a $30 \mathrm{mg}$ single dose of ulipristal acetate was compared head to head with a single $1.5 \mathrm{mg}$ dose of levonorgestrel. The reported pregnancy rates were $1.8 \%$ and $2.6 \%$ in the ulipristal acetate and levonorgestrel groups, respectively, when the medications were taken within 72 hours of unprotected intercourse, a difference that was not statistically different. ${ }^{27}$ Furthermore, women who presented more than 72 hours after unprotected intercourse were also randomized, and in 203 women who received either ulipristal acetate or levonorgestrel between 72 and 120 hours, three pregnancies were reported, all of which were in the levonorgestrel group. In this study, the authors also performed a meta-analysis, combining their study with the results reported by Crenin et al. ${ }^{38}$ Combination of the two studies increased the sample size dramatically, and in this combined analysis, ulipristal acetate decreased the risk of pregnancy by half when compared with levonorgestrel, demonstrating its superior efficacy (odds ratio 0.55 , confidence interval 0.32-0.93)..$^{27,41}$

Currently in the US, ulipristal acetate is licensed as an emergency contraceptive to be taken in a single $30 \mathrm{mg}$ dose up to 5 days (120 hours) following unprotected intercourse, making it the only hormonal medication currently on the market approved for use up to 5 days following unprotected intercourse. ${ }^{42}$ The copper IUD is also efficacious up to 5 days following unprotected intercourse, but obviously requires that a woman present to a licensed care provider trained in inserting IUDs within this time interval, making it a less convenient option. Side effects reported with ulipristal acetate have generally been mild, and include headache, nausea, and abdominal pain. ${ }^{40}$ The frequency with which such side effects are reported are comparable with those seen using the levonorgestrel regimen. ${ }^{40}$
Another consistent finding among the trials evaluating ulipristal acetate is that it causes a delay in the next menstrual cycle, which on average is approximately 2 days. ${ }^{38,40}$ This short menstrual delay has also been reported in conjunction with mifepristone, and has been touted as a downside of the progesterone receptor modulators as a class, because menstrual delay may cause anxiety about a potential pregnancy. However, with appropriate counseling by a health care professional, women can be reassured regarding this minor delay in the onset of menses, and should still be urged to seek a pregnancy test if their menstrual cycle is delayed by over 1 week.

Studies evaluating the mechanism through which ulipristal acetate inhibits pregnancy have shown that one mechanism of action is via inhibition of ovulation. In an interesting study by Brache et al women who were surgically sterilized were treated with a $30 \mathrm{mg}$ dose of ulipristal acetate to determine its ability to block follicular rupture in the late follicular phase, once a lead follicle of $18 \mathrm{~mm}$ or greater was seen on ultrasonography. ${ }^{42}$ Additionally, serial luteinizing hormone, estradiol, and progesterone levels were assessed before and for five days after administration of ulipristal acetate. The authors demonstrated that follicular rupture was delayed for at least five days following ulipristal acetate administration in $59 \%$ of cycles. Furthermore, when ulipristal acetate was given prior to the luteinizing hormone surge, follicular rupture was delayed $100 \%$ of the time, and when ulipristal acetate was given after initiation but prior to the peak of the luteinizing hormone surge, follicular rupture was blocked in $78.6 \%$ of cases. Only when ulipristal acetate was administered after the peak of the luteinizing hormone surge did it fail to block follicular rupture. In similar studies conducted by the same authors, levonorgestrel was able to delay follicle rupture in only $14.6 \%$ of cycles when administered with a lead follicle $18 \mathrm{~mm}$ or greater, and this may account for the higher efficacy of ulipristal acetate in preventing pregnancy. ${ }^{18,43}$ The authors additionally commented that, although follicular rupture was delayed by 5 or more days in the majority of the women treated with ulipristal acetate, follicular rupture ultimately did occur at a later time point in the cycle, indicating that ulipristal acetate is effective in preventing pregnancy for up to 5 days after unprotected intercourse, but that if a woman has additional acts of coitus after taking ulipristal acetate, she is still at risk of pregnancy. ${ }^{42}$

\section{Current challenges with emergency contraception}

Efficient utilization of EC to prevent unwanted pregnancies is an example of the evolution of type 3 translational 
research. Translational research generally describes the progression of taking discoveries in basic science and translating them into clinical medicine to promote the health of a population. Type 3 translational research specifically describes the process of taking a medication or intervention proven to be effective in large, randomized trials and implementing its routine use by the necessary cohort of physicians such that the population as a whole is exposed to and derives benefit from the medication and/or intervention. Addressing the question of why medications or interventions demonstrated to be effective in the research setting are not routinely utilized in large populations is the cornerstone of type 3 translational research, and is an important component of current research in EC. As discussed earlier, current EC regimens have been demonstrated to be highly effective in preventing pregnancy. However, despite the fact that specific EC products have been marketed in the US since the late 1990s, unintended pregnancy rates and abortion rates, both in the US and globally, have not changed significantly. ${ }^{10,44,45}$ Indeed, a study describing the potential of EC projected that widespread utilization could decrease the abortion rate in the US by half. ${ }^{1}$ Thus, answering the question of why enhanced availability of EC has not impacted the incidence of unintended pregnancy as had been projected remains critical in the field of women's health.

Initial attempts to address this question have focused on access to $\mathrm{EC}$ as an important factor in increasing usage. Clearly, given the limited time interval in which EC must be taken, easy access to the medication is essential. Prior to approval of over-the-counter sale of the levonorgestrel regimen (plan B) by the FDA in 2006, several studies assessed the impact of increasing access to EC. A study published in 2005 compared usage rates of EC among women who were given levonorgestrel tablets to keep at home, those who could access the medication via a pharmacy without a prescription, and those who could only access the medication by presenting to a clinic. ${ }^{46}$ The authors demonstrated that women who were given the medication to keep at home were twice as likely to use it compared with the other two groups, even though the frequency of unprotected intercourse in the three groups was similar. Interestingly, women who had access to EC through a pharmacy were not significantly more likely to utilize EC than those who had to present to a clinic to obtain the medication. A recent meta-analysis describing the results of many similar trials corroborated this finding, demonstrating that increased access to EC does increase use. ${ }^{44}$ One of the biggest concerns regarding increasing access to $\mathrm{EC}$ is whether such access will promote sexually risky behavior and increase the incidence of STIs. However, several studies have now demonstrated that advance provision of EC to women does not increase the incidence of unprotected intercourse, decrease the rate of consistent contraceptive use, or increase the rate of STIs. ${ }^{46-51}$ Thus, such arguments against making EC widely accessible appear unwarranted.

Although access to EC has consistently improved over the years, some significant limitations still exist. In the US, only women over the age of 16 years are able to access EC without a prescription. This significantly limits access to a population where unintended pregnancy rates are the highest, because approximately $80 \%$ of teenage pregnancies are unintended and contribute $25 \%$ or more to the unplanned pregnancy rate annually in the US. ${ }^{52}$ Furthermore, many teens and young adults report that the current cost (generally around US\$50 when purchased in a pharmacy) is a significant impediment to accessing EC. In a study performed in New York City where indepth interviews were conducted with teens and young adults, many respondents expressed disbelief that anyone would pay US\$ 50 to obtain EC, especially when "it might not even work." 53 Thus, eliminating the age restriction to allow access to $\mathrm{EC}$ without a prescription for all women, and working to reduce the current cost of EC in pharmacies are two major components that must be addressed in order to provide widespread access to EC. However, although multiple studies have demonstrated that increased access to EC does increase use, such studies have also clearly demonstrated that increased use of EC is not translating into a notable decrease in the unintended pregnancy rate. ${ }^{44}$ Thus, other barriers aside from access must be at work in impeding the realization of the true potential of EC to decrease unintended pregnancy rates.

One such barrier that has more recently come to light is the limited knowledge that many people have in regards to EC. In a survey conducted in California in 2003 by the Kaiser Family Foundation, where over 1000 men and women aged 15-44 years participated, several of these knowledge gaps were highlighted. ${ }^{54}$ For example, when asked if they had heard of EC or the "morning-after pill," the majority of respondents (78\%) indicated that they were familiar with EC. However, when asked whether there was something a woman could do to prevent pregnancy after unprotected intercourse or contraceptive failure, only about one third of adults indicated that they understood that EC could be used in this situation. This underscores the fact that, although most men and women of reproductive age are familiar with the term EC or the "morning-after pill," the majority of them do not actually 
understand what it does. Furthermore, this survey, as well as other research, has demonstrated that there is significant confusion between EC and RU-486 or mifepristone, commonly referred to as the "abortion pill" by the lay public in the US. ${ }^{53-55}$ In the Kaiser Family Foundation survey, respondents were asked whether the following statement was true or false: "Emergency contraceptive pills are another term for RU-486, the 'abortion pill'." Fifty percent of participants indicated that they thought this was a true statement. ${ }^{54}$ Unfortunately, several years later and following the change of the levonorgestrel regimen to over-the-counter status by the FDA, such misconceptions are still fairly common.

A recent study conducted among adolescents aged 15-21 years in New York City in 2010 mirrored the findings of the Kaiser Family Foundation in that the majority of respondents, while stating that they were familiar with EC or Plan B, frequently still said no when asked if there was something they could do to prevent pregnancy after sexual intercourse. ${ }^{53}$ Many also still confused EC with RU-486. Additionally, a prominent trend noted by the investigators conducting the interviews was that there was "a clear disconnect between the desire [of teens] not to be pregnant and the willingness to take proactive measures to prevent pregnancy." ${ }^{53}$ Other studies have reflected the same belief. When determining the proportion of women who became unintentionally pregnant during trials assessing the use of EC, under $30 \%$ of women actually used EC in the menstrual cycle in which they became pregnant, even when EC was readily available. Responses given for the failure to use EC demonstrated that many women fail to recognize the risk of pregnancy, even when the timing of intercourse is close to ovulation. These findings point to the need for significant public education campaigns to educate women better regarding how and when to use $\mathrm{EC}$ if the rates of unintended pregnancy and abortion are actually to be decreased.

Finally, not only are public awareness campaigns necessary, but improved counseling by providers of women's health is also paramount to educate women better about EC. Currently, of women familiar with EC, only 10\% learned about it from a health professional. ${ }^{54}$ Even if women had a gynecologic visit within the past year, only $13 \%$ report that their physician discussed EC. Surveys among practicing physicians support this general lack of counseling. In a survey from 2001 , only $25 \%$ of gynecologists and $14 \%$ of general practice physicians report discussing EC as a backup method of contraception "always" or "most" of the time. ${ }^{56}$ However, such counseling from physicians likely plays a significant role in whether women actually are motivated to use EC after unprotected intercourse or contraceptive failure. The majority of women reported being more likely to take EC if a doctor had informed and counseled them about this option. ${ }^{54}$ Furthermore, research demonstrates that many primary care physicians themselves require further education about prescribing EC, because surveys among physicians often cite lack of familiarity, concern with increasing rates of STIs, and concern about potential teratogenicity as barriers to routine prescribing. ${ }^{57-60}$ In a recent survey of pediatric emergency room physicians, although the vast majority had prescribed $\mathrm{EC}$ at some point in the past, most reported prescribing EC five or fewer times. ${ }^{60}$ Most physicians cited one or more barriers to EC prescribing, including concern about lack of follow-up, time constraints, lack of clinical resources, discouraging regular contraceptive use, and concern about birth defects. Furthermore, 43\% of respondents were not able to answer half of the knowledge-based questions in the survey correctly.

Given that teens younger than 17 years in the US still require a prescription to obtain $\mathrm{EC}$ and the emergency room is a likely place for them to go, it is concerning that a significant number of pediatric ER physicians have limited knowledge regarding appropriate prescribing and unfounded concerns about barriers with EC. Further education of all practitioners who routinely provide care to women of reproductive age is vital, with special emphasis on the timing of EC, its safety and efficacy, even if taken multiple times, and its lack of association with teratogenicity.

\section{Future directions COX-2 inhibitors}

Utilizing cyclo-oxygenase (COX)-2 inhibitors to delay or prevent ovulation for the purpose of EC is another research focus on the horizon. Prostaglandins are known to be important in many aspects of ovulation, such as cumulus expansion and augmentation of protease activity, which leads to extracellular matrix degradation. ${ }^{61}$ Both of these processes are critical to successful ovulation, and COX-2 enzymes are essential in the production of prostaglandins within the ovarian follicle.

In a recent study by Hester et al primates were treated with meloxicam, a COX-2 inhibitor, for 5 consecutive days starting either in the mid follicular, late follicular, or periovulatory phase of the menstrual cycle. ${ }^{61}$ The investigators demonstrated that ovulation was blocked in $67 \%$ of cycles when meloxicam was administered in the mid follicular phase, $100 \%$ of cycles when administered in the late follicular phase, and in only $50 \%$ of cycles when administered in the periovulatory phase. 
In the study, the ovaries were removed following treatment with meloxicam, and the investigators demonstrated that the majority of the follicles still retained their oocyte, suggesting that inhibition of oocyte release, either through failure of cumulus expansion or failure of the breakdown of the follicular wall, may be the mechanism through which the COX-2 inhibitor works. ${ }^{61}$

In a similar study conducted in humans, women who were surgically sterilized were treated with either $15 \mathrm{mg}$ or $30 \mathrm{mg}$ meloxicam for 5 days in the late follicular phase, starting when the lead follicle was noted to be $18 \mathrm{~mm}$ on ultrasound. ${ }^{62}$ When administered at the $30 \mathrm{mg}$ dose, meloxicam was demonstrated to inhibit follicle rupture during the six-day observation period in $45.5 \%$ of cycles, and to cause ovulatory dysfunction (defined as follicle rupture not preceded by a luteinizing hormone peak or preceded by a blunted luteinizing hormone peak or not followed by an appropriate progesterone rise) in an additional $45.5 \%$ of cycles. Interestingly, even when meloxicam was administered after the peak of the luteinizing hormone surge, it was still able to cause ovulatory dysfunction in $75 \%$ (six of eight) of women. The authors concluded that this may be the biggest benefit of COX-2 inhibitors over levonorgestrel, because it has been demonstrated that levonorgestrel is no longer effective at delaying ovulation when administered after the peak of the luteinizing hormone surge. ${ }^{62}$ Finally, when administered in conjunction with $1.5 \mathrm{mg}$ levonorgestrel once the lead follicle is $>18 \mathrm{~mm}$, Massai et al have shown that $15 \mathrm{mg}$ of meloxicam can increase the incidence of failed follicular rupture from $16 \%$ to $39 \%$. $^{43}$ Thus, COX-2 inhibitors may ultimately play a role, either independently or when used in conjunction with hormonal methods, in increasing the efficacy of EC. However, large-scale clinical trials demonstrating efficacy in preventing pregnancy are necessary before COX-2 inhibitors become a potential clinical option.

\section{Conclusion}

Emergency contraception is currently accessible in over 140 countries. ${ }^{27}$ Emergency contraceptive options, such as the levonorgestrel regimen, selective progesterone receptor modulators, the Yuzpe regimen, and insertion of a copper IUD, have all been demonstrated to be efficacious in preventing unplanned pregnancies following unprotected or underprotected intercourse. However, despite the increased availability of EC over the past decade, no study to date has been able to demonstrate a reduction in unplanned pregnancy and/or abortion rates worldwide. This finding is felt to be at least partly due to an underutilization of current
EC methods. Thus, it is imperative that future research not only addresses the efficacy of various methods of EC, but also that it focuses on how to advance awareness and better educate women about accessing and utilizing EC when necessary, if a reduction in the abortion rate worldwide is to be realized.

\section{Disclosure}

The authors report no conflicts of interest in this work.

\section{References}

1. Trussell J, Stewart F, Guest F, Hatcher RA. Emergency contraceptive pills: a simple proposal to reduce unintended pregnancies. Fam Plann Perspect. 1992;24:269-273.

2. Alan Guttmacher Institute. US Teenage pregnancies, births and abortions: National and state trends by race and ethnicity. Available at: http://www. guttmacher.org/pubs/USTPtrends.pdf. Accessed July 12, 2011.

3. Dailard C. Abortion in context: United States and worldwide. 1999 Available from: http://www.guttmacher.org/pubs/ib_0599.html. Accessed July 12, 2011.

4. Black KI. Developments and challenges in emergency contraception. Best Pract Res Clin Obstet Gynaecol. 2009;23:221-231.

5. Sanfilippo J, Downing D. Emergency contraception: when and how to use it. J Fam Pract. 2008;57(Suppl 2):S25-S36.

6. World Health Organization. Medical eligibility criteria for contraceptive use. 3rd ed. Geneva, Switzerland: World Health Organization; 2004.

7. American College of Obstetricians and Gynecologist. ACOG Practice Bulletin No. 112: emergency contraception. Obstet Gynecol. 2010; 115:1100-1109.

8. Yuzpe A, Lancee WJ. Ethinylestradiol and dl-Norgestrel as a postcoital contraceptive. Fertil Steril. 1977;28:932-936.

9. Task Force on Postovulatory Method of Fertility Regulation. Randomized controlled trial of levonorgestrel versus Yupze regimen of combined oral contraceptives of emergency contraception. Lancet. 1998;352:428-433.

10. Cheng L, Gulmezoglu AM, Piaggio GGP, Ezcurra EE, Van Look PPFA. Interventions for emergency contraception. Cochrane Database Syst Rev. 2008;2:CD001324.

11. Ho PC, Kwan MS. A prospective randomized comparison of levonorgestrel with the Yuzpe regien in post-coital contraception. Hum Reprod. 1993;8:389-392.

12. Arowojolu AO, Okewole IA, Adekunle AO. Comparative evaluation of the effectiveness and safety of two regimens of levonorgestrel for emergency contraception in Nigerians. Contraception. 2002;66: 269-273.

13. Von Hertzen H, Piaggio G, Ding J, et al. Low dose mifepristone and two regimens of levonorgestrel for emergency contraception:a WHO multicenter randomized trial. Lancet. 2002;360:1803-1810.

14. Raymond E, Taylor D, Trussell J, Steiner MJ. Minimum effectiveness of the levonorgestrel regimen of emergency contraception. Contraception. 2004;69:79-81.

15. Ellertson C, Webb A, Blanchard K, et al. Modifying of the Yuzpe regimen of emergency contraception: a randomized, controlled, multicenter trial. Obstet Gynecol. 2003;101:1160-1167.

16. Trussell J, Ellertson C, von Hertzen $\mathrm{H}$, et al. Estimating the effectiveness of emergency contraceptive pills. Contraception. 2003;67:259-265.

17. Hapangama DK, Glasier AF, Baird DT. The effects of peri-ovulatory administration of levonorgestrel on the menstrual cycle. Contraception. 2001;63:123-129.

18. Croxatto HB, Brache V, Pavez M, et al. Pituitary-ovarian function following the standard levonorgestrel emergency contraceptive dose or a single 0.75 -mg dose given on the days preceding ovulation. Contraception. 2004; 70:442-450. 
19. Gemzell-Danielsson K. Mechanism of action of emergency contraception. Contraception. 2010;82:404-409.

20. Bahamondes L, Nascimento JAA, Munuce MJ, Fazano F, Faundes A. The in vitro effect of levonorgestrel on the acrosome reaction of human spermatozoa from fertile men. Contraception. 2003;68:55-59.

21. Yeung WSB, Chiu PCN, Wang CHYQ, Yao YQ, Ho PC. The effects of levonorgestrel on various sperm functions. Contraception. 2002;66: 453-457.

22. Do Nascimento JA, Seppala M, Perdigao A, et al. In vivo assessment of the human sperm acrosome reaction and the expression of glycodelin-A in human endometrium after levonorgestrel-emergency contraceptive pill administration. Hum Reprod. 2007;22:2190-2195.

23. Durand M, del Carmen CM, Raymond EG, et al. On the mechanism of action of short-term levonorgestrel administration in emergency contraception. Contraception. 2001;64:227-234.

24. Marions L, Hultenby K, Lindell I, Sun X, Stabi B, Gemzell-Danielsson K. Emergency contraception with mifepristone and levonorgestrel: mechanism of action. Obstet Gynecol. 2002;100:65-71.

25. Novikova N, Weisberg E, Stanczyk FZ, Croxatto HB, Fraser IS. Effectiveness of levonorgestrel emergency contraception given before or after ovulation - a pilot study. Contraception. 2007;75:112-118.

26. Noe G, Croxatto HB, Salvatierra AM, et al. Contraceptive efficacy of emergency contraception with levonorgestrel given before or after ovulation. Contraception. 2010;81:414-420.

27. Glasier AF, Cameron ST, Fine PM, et al. Ulipristal acetate versus levonorgestrel for emergency contraception: a randomized noninferiority trial and meta-analysis. Lancet. 2010;375:555-562.

28. US Food and Drug Administration. Prescription drug products; certain combined oral contraceptives for use as postcoital emergency contraception; notice. Federal Register. 1997;62: 8609-8612. Available from: http://www.hhs.gov/opa/familyplanning/toolsdocs/opa97-2_attach2. pdf. Accessed Aug 19, 2011.

29. Trussell J, Hedley A, Raymond E. Ectopic pregnancy following use of progestin-only ECPs. J Fam Plann Reprod Health Care. 2003;29:249.

30. Rovi S, Shimoni N. Prophylaxis provided to sexual assault victims seen in US emergency departments. $J$ Am Med Womens Assoc. 2002;57: 204-207.

31. Merchant RC, Phillips BZ, Delong AK, Mayer KH, Becker BM. Disparities in the provision of sexually transmitted disease and pregnancy testing and prophylaxis for sexually assaulted women in Rhode Island emergency departments. $J$ Womens Health (Larchmt). 2008; 17:619-629.

32. Liying Z, Bilian X. Emergency contraception with Multiload Cu-375 SL IUD: a multicenter clinical trial. Contraception. 2001;64: 107-112.

33. Trussell J, Koenig J, Ellerton C, et al. Preventing unintended pregnancy: the cost-effectiveness of three methods of emergency contraception. $\mathrm{Am}$ J Public Health. 1997;87:932-937.

34. Jonsson B, Landgren B, Eneroth P. Effects of various IUDs on the composition of cervical mucus. Contraception. 1991;43:447-457.

35. Ortiz M, Croxatto M. The mode of action of IUDs. Contraception. 1987;36:37-53.

36. Stanford J, Mikolajczyk R. Mechanism of action of intrauterine devices: update and estimation of postfertilization effects. Am JObstet Gyencol. 2002;187:1699-1708.

37. Faundes A, Telles E, Cristofoletti ML, Faundes D, Castro S, Hardy E. The risk of inadvertent intrauterine device insertion in women carriers of endocervical Chlamydia trachomatis. Contraception. 1998;54: 105-109.

38. Crenin MD, Schlaff W, Archer DF, et al. Progesterone receptor modulator for emergency contraception: a randomized controlled trial. Obstet Gynecol. 2006;108:1089-1097.

39. Ashok P, Stalder C, Wagaarachchi P, et al. A randomized study comparing a low dose of mifeprisotne and the Yuzpe regimen for emergency contraception. Br J Obstet Gynaecol. 2002;109:553-560.

40. Fine P, Mathe H, Ginde S, Cullins V, Morfesis J, Gainer E. Ulipristal acetate taken 48-120 hours after intercourse for emergency contraception. Obstet Gynecol. 2010;115:257-263.
41. Gemzell-Danielsson K, Meng C. Emergency contraception: potential role of ulipristal acetate. Int $J$ Women's Health. 2010;2:53-61.

42. Brache V, Cochon L, Jesam C, et al. Immediate pre-ovulatory administration of $30 \mathrm{mg}$ ulipristal acetate significantly delays follicular rupture. Hum Reprod. 2010;25:2256-2263.

43. Massai MR, Forcello ML, Brache V, et al. Does meloxicam increase the incidence of anovulation induced by single administration of levonorgestrel in emergency contraception? a pilot study. Hum Reprod. 2007;22:434-439.

44. Raymond EG, Trussell J, Polis CB. Population effect of increased access to emergency contraceptive pills: a systematic review. Obstet Gynecol. 2007;109:181-188.

45. Lakha F, Glasier A. Unintended pregnancy and use of emergency contraception among a large cohort of women attending for antenatal care or abortion in Scotland. Lancet. 2006;386:1782-1787.

46. Raine TR, Harper CC, Rocca CH, et al. Direct access to emergency contraception through pharmacies and effect on unintended pregnancy and STI: a randomized controlled trial. JAMA. 2005;293: 54-62.

47. Gold MA, Wolford JE, Smith KA, Parker AM. The effects of advanced provision of emergency contraception on adolescent women's sexual and contraceptive behaviors. J Pediatr Adolesc Gynecol. 2004;17: $87-96$.

48. Ellertson C, Ambardekar S, Hedley A, Coyaji K, Trussell J, Blanchard K. Emergency contraception: randomized comparison of advanced provision and information only. Obstet Gynecol. 2001;98:570-575.

49. Glasier A, Baird D. The effects of self-administering emergency contraception. N Engl J Med. 1998;339:1-4.

50. Jackson RA, Schwarz EB, Freedman L, Darney P. Advance supply of emergency contraception: effect on use and usual contraception a randomized trial. Obstet Gynecol. 2003;102:8-16.

51. Lo SS, Fan SY, Ho PC, Glasier AF. Effect of advanced provision of emergency contraception on women's contraceptive behaviour: a randomized controlled trial. Hum Reprod. 2004;19:2404-2410.

52. Guttmacher Institute. Facts on American Teen's Sexual and Reproductive Health. Available from: http://www.guttmacher.org/pubs/fb_ATSRH. html. Accessed July 12, 2011.

53. Johnson R, Nshom M, Nye AM, Cohall AT. There's always Plan B: adolescent knowledge, attitudes and intention to use emergency contraception. Contraception. 2010;81:128-132.

54. Salganicoff A, Wentworth B, Ranji U. Emergency contraception in California: findings from a 2003 Kaiser Family Foundation survey. The Kaiser Family Foundation. February, 2004. Available from: http://www. kff.org/womenshealth/upload/Emergency-Contraception-in-California. pdf. Accessed December 14, 2010.

55. Mollen CJ, Barg FK, Hayes KL, Gotcsik M, Blades MN, Schwarz DF. Assessing attitudes about emergency contraception among urban, minority adolescent girls: an in-depth interview study. Pediatrics. 2008;122:e395-e401.

56. Kaiser Family Foundation. Survey Snapshot: women's health care providers' experience with emergency contraception. 2003. Available from: http://www.kff.org/womenshealth/upload/Women-s-Health-CareProviders-Experiences-with-Emergency-Contraception.pdf. Accessed December 14, 2010

57. Gold MA, Schein A, Coupey SM. Emergency contraception: a national survey of adolescent health experts. Fam Plann Perspect. 1997;29: $15-24$.

58. Golden NH, Seigel WM, Fisher M, et al. Emergency contraception: pediatricians' knowledge, attitudes, and opinions. Pediatrics. 2001;107: 287-292.

59. Wallace JL, Wu J, Weinstein J, et al. Emergency contraception: knowledge and attitudes of family medicine providers. Fam Med. 2004;36:417-422.

60. Goyal M, Zhao H, Mollen C. Exploring emergency contraception knowledge, prescription practices, and barriers to prescription for adolescents in the emergency department. Pediatrics. 2009;123: 765-770. 
61. Hester KE, Harper MJK, Duffy DM. Oral administration of the cyclooxygenase-2 (COX-2) inhibitor meloxicam blocks ovulation in non-human primates when administered to simulate emergency contraception. Hum Reprod. 2010;25:360-367.
62. Jesam C, Salvatierra AM, Schwartz JL, Croxatto HB. Suppression of follicular rupture with meloxicam, a cyclooxygenase-2 inhibitor: potential for emergency contraception. Hum Reprod. 2010;25: 368-373.

\section{Publish your work in this journal}

Open Access Journal of Contraception is an international, peerreviewed, open access, online journal, publishing original research, reports, reviews and commentaries on all areas of contraception. In addition to clinical research, demographics and health-related aspects, the journal welcomes new findings in animal and preclinical studies relating to understanding the biological mechanisms and practical development of new contraceptive agents. The manuscript management system is completely online and includes a very quick and fair peer-review system. Visit http://www.dovepress.com/testimonials.php to read real quotes from published authors.

Submit your manuscript here: http://www.dovepress.com/open-access-journal-of-contraception-journal 